\title{
The MPAcc Talent Development Features Research Based on Regional Economics
}

\author{
Jun Dai ${ }^{1, a,{ }^{*}}$ and Danfeng Wen ${ }^{1}$ \\ ${ }^{1}$ School of Management, Wuhan University of Science and Technology, Wuhan, Hubei, China \\ adaijun78@wust.edu.cn \\ *corresponding author
}

Keywords: Master of Professional Accounting; Regional Economics; Hubei Free Trade Area, Made in China 2025

\begin{abstract}
Where does the MPAcc talents cultivation features come from? This paper is devoted to solve this issue by exploring the requirements of Hubei Province economical development for the senior accounting talents and the hotspots of the local macro economic reforms, such as 'Hubei Free Trade Area' and 'Hubei Action Scheme of Made in China 2025'. By overall systematic analysis, we suggest that the MPAcc talents training plans must be designed in close conjunction with the cultivation of 'decision ability, innovation, concerning foreign, finance and IT'. Only in this way, it can meet the requirement of Hubei economical development for the advanced accounting talents. Hopefully, this study could make some contributions to drafting scientific MPAcc talent development schemes for the regional colleges and universities.
\end{abstract}

\section{Introduction}

Hubei province, the big education province, has eleven MPAcc training universities up to December 2017, which consists of five universities under the Ministry of Education represented by Wuhan University, five local universities represented by Wuhan Textile University, and one military college. Hubei province is a microcosm of all Chinese MPAcc training situations that the rapid increase of training units intensifies the enrolment competition of high-quality students. Due to a short history of MPAcc training, the weakness of teaching and research compared with comprehensive key universities or colleges of finance and economics, the local MPAcc training universities can win an edge over competitors in the MPAcc training only by developing characteristic education. Where does the MPAcc talents cultivation features come from? This paper is devoted to solve this issue by exploring the requirements for the advance accounting talents induced by the Hubei Province economical development and the hotspots of the local macro economic reforms, such as 'Hubei Free Trade Area' and 'Hubei Action Scheme of Made in China 2025'.

\section{Current Situation Of Mpacc Talent Culitvation In Hubei Province}

Early in 2004, key Wuhan University and Zhongnan University of Economics and Law in Wuhan are first MPAcc training units approved by Ministry of Education together with Beijing University and Qinghua University. In the following 10 years time, a total of 11 universities and colleges represented by Huazhong University of Science and Technology, Wuhan University of Technology have achieved the mission of MPAcc training, in which two universities are the fifth batch of MPAcc training units in 2017. According the 2016 year enrollment information statistics of MPACC training centers in the first four batches of 9 units, Hubei MPAcc enrollment statistics in 2016 are as shown in Figure 1. 


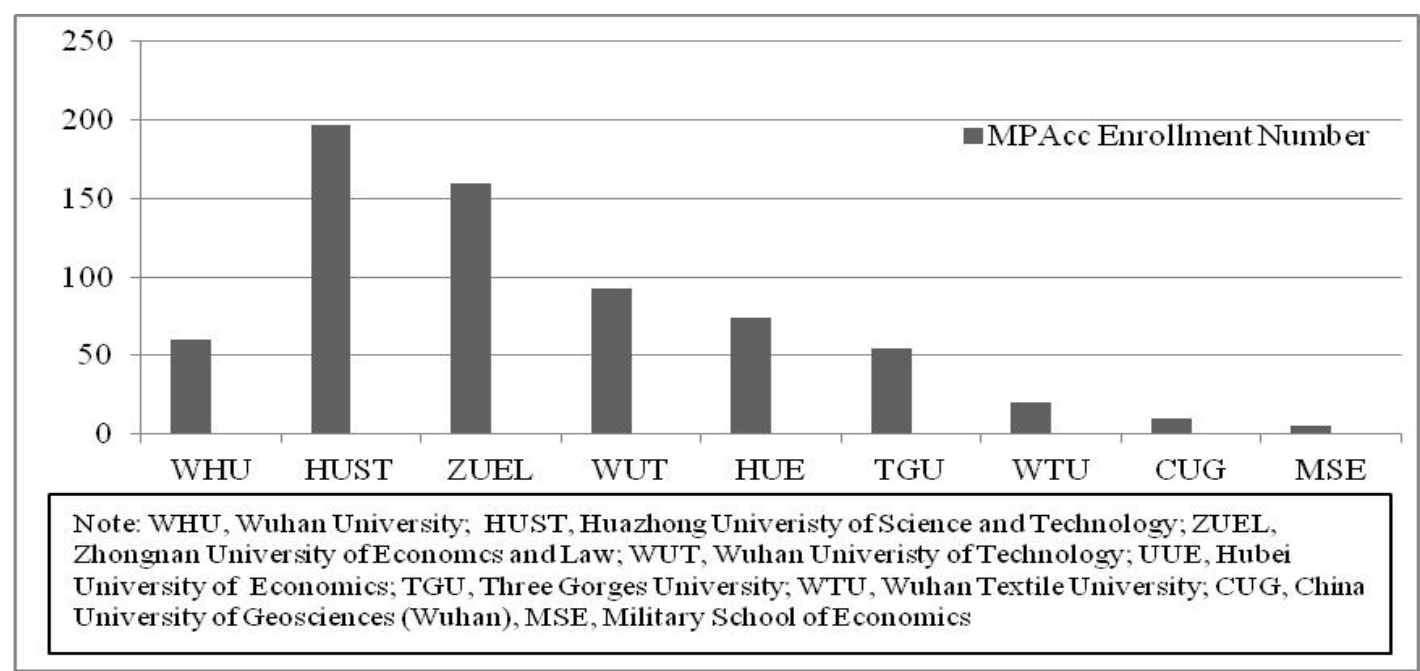

Figure 1 The Hubei province university MPAcc enrollment statistics

From the perspective of enrollment, the scale of MPAcc in Hubei has ranked second in China, which is less than Beijing with 1200 enrollment and more the Shanghai with 500 students enrolled by 8 MPAcc training units. Thus it can be seen that the MPAcc training in Hubei has gradually taken shape, and has already served as a base for fostering senior accounting talents in Central China and even the whole China.

As to the training target of MPAcc talents, besides training the applied talents as core, some Hubei local universities tried to sum up the main characteristics based on their industrial and regional advantages. For example, the Three Gorges University located in Hubei Yichang city puts forward to serve the hydraulic and electric engineering industry and regional economic development surrounding Three Gorges area as its guiding principle, and takes cultivating highly skilled, ethical, compound and practical advanced accounting talents who can innovatively solve financial problems of enterprises and institutions as training objective. Hubei University of Economics also stresses its advantage as a university of finance and economics especially in the finance sector, and raises a MPAcc talent target of cultivating applied, compound and advanced high-level talents for small and medium-sized enterprises, financial sector and certified public accountant sector. While, as to the other three Hubei regional universities having the MPAcc educational qualification, no information about their MPAcc-running features can be found on their web homepages.

In the context of boom MPAcc enrollment of Hubei with average acceptance rate increasing to 1 from 7 candidates, the regional MPAcc training universities can maintain a large scale of MPAcc enrollment. However, in the long run, due to the increase of MPAcc graduates stock and the market demand saturation of accounting personnel, the MPAcc training university without predominance or features will surely be left at a disadvantage when they are facing increasingly fierce competition. Therefore in the face of the above challenges, local universities should lost no time in reform, and fosters senior accounting talents according to the demand of Hubei future economic development besides promotion of the traditional industrial and regional advantages. Only in this way can the local MPAcc training universities make a living and better development.

\section{The Feature Analysis Of Feature Analysis Of Mpacc Talents Induced By Hubei Furutre Economic Development}

\subsection{The potential demand for MPAcc talents from the Hubei Free Trade Area}

In the framework of macro economic reforms of 'Belt and Road', 'Made in China 2015', and 'Free Trade Zone and Yangtze River Economic Belt', China State Department decided to set up free trade area in Hubei and other 6 provinces on August 2016. On the next April 1, 2017 China Hubei Free Trade Area was officially established. As the first batch of free trade areas in inland, Hubei Free 
Trade Area carries out pilot work in the fields of investment and trade facilitation, system innovation in the administrative agencies of government, scientific and financial sectors.

By this opportunity, Hubei Free Trade Area will surely create a need for high-lever trade, finance and accounting expertise. Specifically, firstly the demand for foreign accounting talents will increase fast. As the opening level of local economics is further deepened by the Hubei Free Trade Area, Hubei must have more frequent economic and trade exchanges and good cooperation with the 64 countries along the 'the Belt and Road', which will induce rapid growth in talents demand in the areas of foreign related legal, international trade and finance, international accounting standards. Secondly, there will be more market demand for the finance and accounting compound talents in the near future. According to the requirements of Hubei Free Trade Area program, the burgeoning financial industry such as finance lease, angel investment, and securitization, etc. will become the key industries. In addition, according the experience of Shanghai and Tianjin Free Trade Areas, the amount of innovative financial enterprises presented an explosive growth during the free trade area pilot process. Therefore, while the Hubei Free Trade Area reform roll out, Hubei as the financial core of central China will be further enhanced, and regional booming financial industry is going to generate robust demand for the financial and accounting compound talents.

\subsection{The analysis of MPAcc talents demand based on the 'Hubei Action Scheme of Made in China 2025,}

In according with the spirit of 'Hubei Action Scheme of Made in China 2025', Hubei endeavors to achieve the diversion from 'big manufacturing province' to 'strong manufacturing province'. Specifically, it has established the comprehensive transformation and upgrading objective named "Three Areas and One Center', which includes one pilot area of intelligent manufacturing, one core area of high-end manufacturing industry clusters, one demonstration area of industrial reforming promotion, and one innovation center of region leading and national first-class manufacturing. These above series reforms will bring significant changes in management accounting for the Hubei manufacturing industry, and huge demand for new-style management accounting talents.

It is generally known that management accounting can realize growth of enterprise value by the meticulous management, and play an important role in promoting manufacturing industry transitional development. 'Hubei Action Scheme of Made in China 2025' requires the objectives of management accounting converting from the 'cost' orientation to the 'core competence' as guidance. Specifically, by series of management measures, such as performance evaluation, analysis on product value chain, competitor analysis, strategic cost-driver analysis, cost structure optimization and comprehensive budget management, corporate finance department can be transformed into the incubation center of core capability, value creation center for the innovation-driven manufacturing industry. Furthermore, with the implementation of the 'Internet plus', management accounting will develop from the past to rely on single isolated ERP system to the opening accounting information management platform.

In order to achieve 'Hubei Action Scheme of Made in China 2025', MPAcc education needs to build an upgraded version of management accounting personnel and explore new training mode of management accounting talents.

In addition, 'Hubei Action Scheme of Made in China 2025' also set higher requirements for IT skills of accounting talents. With the popularity of Internet plus and cloud computing, the future of enterprise financial activities will also become more and more intelligent. The traditional accounting and preparation of financial statements will be more implemented by the Financial Sharing Center and artificial intelligence system. Relying on mobile internet, big data and cloud computing, financial cloud opens the era of intelligent finance, which includes three parts: Financial Shared Services, financial management and fund management, as shown in Figure 2: 


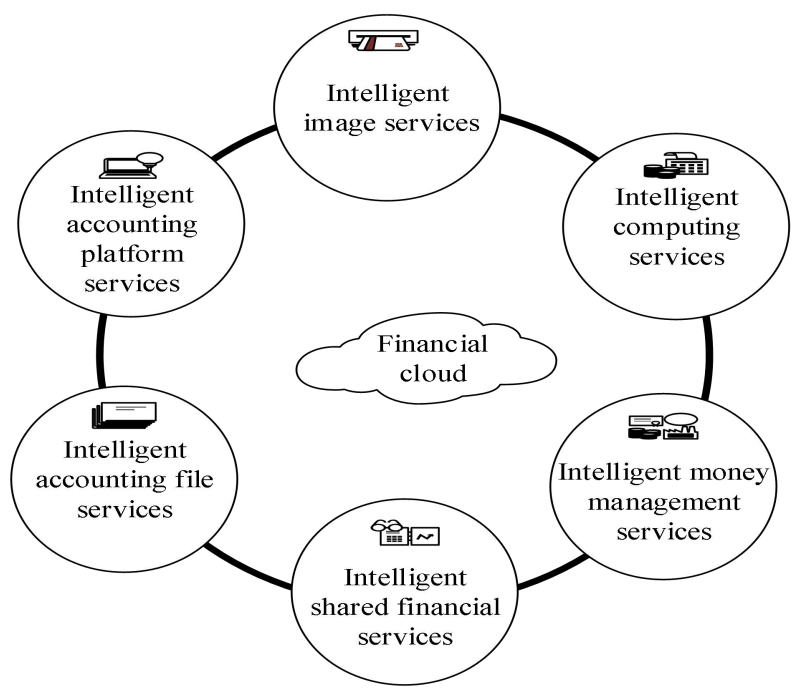

Figure 2 The function of financial clouds

The accounting information, such as the cost and profit produced at any time point, can be updated in a timely manner in the database. The accounting statements can also be disclosed at any time. Eventually, all the financial resources can be shared in real time. Further, it can provide more accurately, timely and completely disclosure of corporate financial information for management. In the future, enterprises need financial staff to focus on higher level information analysis and management decisions, and become designers of enterprise value. The era of intelligent finance, represented by financial cloud, will bring a demand of higher IT skills on accountants. Perhaps in the near future, the senior accountants needed by enterprises will be the best IT talents in accountants or the best accountants in the IT profession.

\section{Reform Of Mpacc Talents Training Model For Regional Economic Development In Hubei}

In order to make MPAcc talent training better meet the needs of the 'Hubei free trade area' and the '2025 Hubei program of action in China' for senior accountants, this paper combs the soft ability framework of high-end financial personnel in the new situation of regional economic development in Hubei, which is as shown in Figure 3.

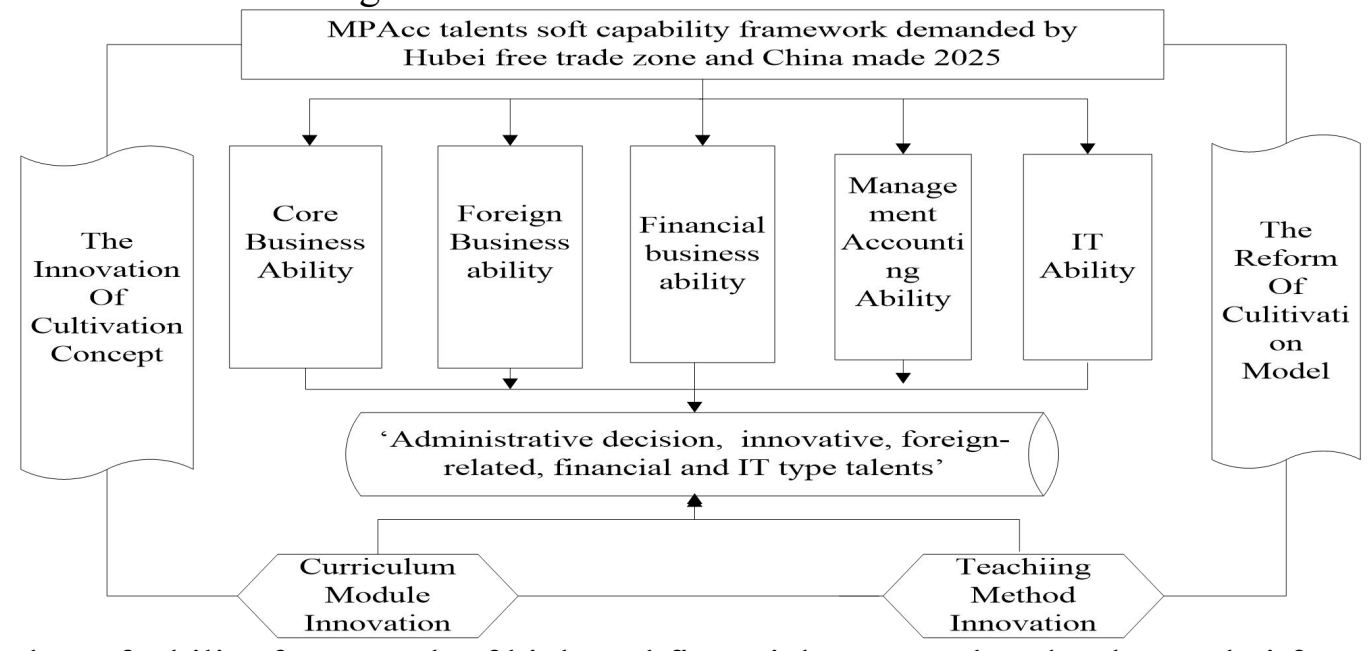

Figure 3 The soft ability framework of high-end financial personnel under the 'Hubei free trade area' and the '2025 Hubei program of action in China'

Focusing on the training objectives of 'administrative decision, innovative, foreign-related, financial and IT type talents', to condense MPAcc training features needs to develop a curriculum module based on the above 'soft capability' cultivation. Specifically, besides the curriculum system 
recommended by MPAcc teaching guiding committee, a series of new elective courses need to be added. The first is to carry out a series of lectures, which is aim to spread the basic knowledge of economic development and taxation etc. along 'The Belt and Road' countries. The second is to set up elective courses involving international trade and finance, business foreign languages and foreign related laws, focusing on training students' foreign business capabilities. The three is to set up the management accounting courses of enterprise risk management, internal control, performance evaluation and company strategy, and cultivate the students' management accounting skills in the aspects of financial planning, control and performance evaluation.

In addition, in order to forge the above 'soft capabilities' of MPAcc, colleges and universities need to make bold innovations in the way of training. Specially, firstly MPAcc training units should endeavor to build 'enterprise and university' cooperating cultivation model by setting up practical teaching base with leading enterprises in the advanced manufacturing and finance industries that are supporting industries of priority in Hubei. In addition, in view of the lack of channels for Hubei local colleges and universities to contact the enterprises in the region, it is suggested that the mechanism of cooperation with the outstanding enterprises of the industry to train MPAcc students can be gradually established by joining the related industry associations, such as the financial sharing Association of Hubei province. Secondly, MPAcc training units should actively promote the teaching mode reform of 'case discussion +ERP management accounting training'. In the formulation of MPAcc training program, it is suggested to increase the proportion of case teaching in management accounting courses, and use special management accounting training software to help students understand and master management accounting theory better and forge the practice of MPAcc students.

\section{Conclusions and Suggestions}

The more the economy develops, the more important the accounting is. Through the previous analysis, It is obviously seen that the training of MPAcc talents in Hubei should closely follow the transformation characteristics of the current regional economic development, and build a talent training program featured by 'decision-making, innovation, foreign-related, financial and IT'. By combing the 'soft ability' of the senior accountants, MPAcc training units should develop a 'soft ability' oriented curriculum and quality development module, and then strive to realize the transformation of MPAcc education from the training of traditional technical talents to the general talents. It is believed that the research findings in this paper will play a positive role in promoting the development of Hubei free trade area and promoting the revitalization of Hubei manufacturing industries.

\section{Acknowledgment}

Supported by the postgraduate education and teaching reform program of Wuhan University of Science and Technology: the training model of local institutes' MPAcc education based on the perspective of regional economic demand (Yjg201606).

\section{References}

[1] Wei QM. "Research on the training mode of accounting talents in Western Local Colleges and Universities- based on the perspective of regional strategy", Studies of finance and accounting in education, 2016, vol. 27, pp. 89-94.

[2] An L.J. "Demand analysis of accounting talents under the background of Liaoning Free Trade Zone Construction", The Journal of economist, 2017, vol. 4, pp. 89-90.

[3] Xue Y., Tan X.H. Innovation of MPAcc training program based on the perspective of regional economy, China Journal of Commerce, 2014, (10): 87-99.

[4] Yang B., Li C.H. "On the path of the cultivation of high-end financial talent service 'The Belt and Road", The journal of development of talent resources, 2015, vol. 6, pp. 70-71. 
[5] Luo L.P., Jiang H.Y. "The exploration of MPAcc education in local universities of science and technology", Survey of Education, 2016, vol. 7, pp. 38-40.

[6] Xi H.J., Xia F., Liao Yu. "Exploration and Practice on Regional International Accountant Talent Training Mode Reform”, Higher Education Forum, 2012, vol. 10, pp. 3-6.

[7] Zhou X.S., Jia J. "A study of accounting professional education in China -- a case study of MPAcc education in Nankai University”, Friends of accounting, 2014, vol. 27, pp.90-99. 